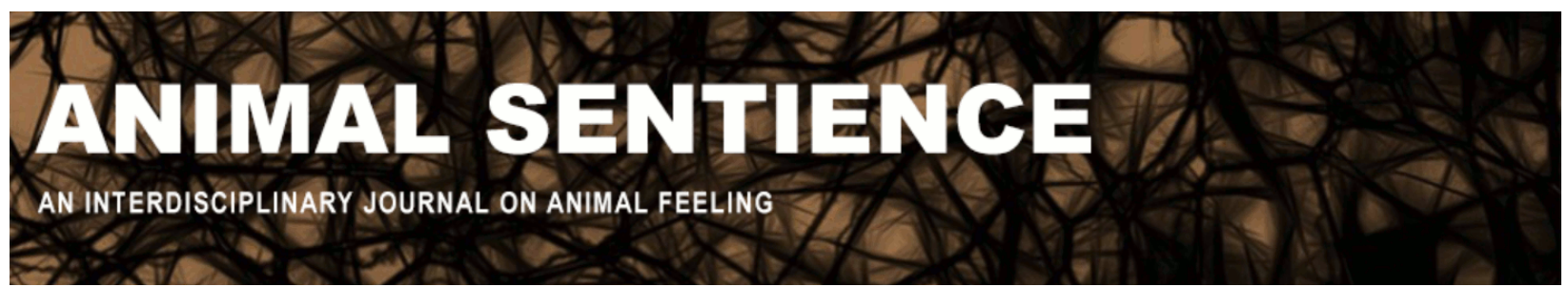

Abbate, Cheryl (2019) Sheep complexity outside the laboratory. Animal Sentience 25(21)

DOI: $10.51291 / 2377-7478.1458$

Date of submission: 2019-05-25

Date of acceptance: 2019-06-01

(c) (†)

This article has appeared in the journal Animal

Sentience, a peer-reviewed journal on animal

cognition and feeling. It has been made open access,

free for all, by WellBeing International and deposited

in the WBI Studies Repository. For more information,

please contact

wbisr-info@wellbeingintl.org.

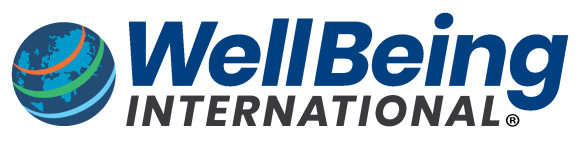

SOLUTIONS FOR PEOPLE, ANIMALS AND ENVIRONMENT 


\title{
Sheep complexity outside the laboratory
}

Commentary on Marino \& Merskin on Sheep Complexity

\author{
Cheryl Abbate \\ University of Colorado Boulder
}

\begin{abstract}
Marino \& Merskin's review shows that sheep are intelligent and highly social but their methodology has some shortcomings. I describe five problems with reviewing only the academic and scientific literature and suggest how one might provide an even more compelling case for the complexity of sheep minds.
\end{abstract}

Cheryl Abbate is an instructor at University of Colorado Boulder. She specializes in nonhuman animal ethics, especially animal rights theory. Website

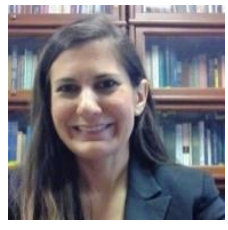

Artificial Environments. Marino \& Merskin (2019) (M\&M) search the scientific literature on sheep cognition and behavior. Their reference list is quite impressive, but they fail to consult perhaps the most important "experts": animal sanctuary workers, who may be in a better position to describe sheep cognition and behavior. Scientists, for a few months or years, study sheep navigating human constructed mazes or reacting to mirrors and photographs of celebrities on computers. M\&M admit that the studies are imperfect, noting that "most research on sheep is driven by the commercial need to increase the efficiency of processing them as meat." Why not draw also on the observations of those who frequently interact with sheep in non-exploitative and relatively natural environments?

Absence of Anecdotes. Missing from M\&M's review are important anecdotes about sheep behavior. M\&M cite a study by Kendrick et al. (2001) on sheep memory reporting that sheep can remember fifty other individual sheep for two years. Readers are left wondering about the history behind this outcome: Where did the sheep originally meet? Where were they reunited? What did the sheep do when they saw one another after two years apart?

The public's reaction to the famous story of Christian the lion demonstrates the power of anecdotes. After being separated from the humans who raised him, Christian was reunited with his former guardians one year later. During this reunion, which is captured on video, a clearly excited Christian ran directly to his former guardians, playfully jumped on them, and, with obvious fondness, "hugged" and nuzzled them repeatedly. This story about one lion - a lion with a name - touched the hearts of many. I show this video to my students when teaching animal ethics, and it never fails to bring students to tears. Yet I suspect there would be quite a different reaction if I simply reported that "lions remember individual humans for X number of years." It is one thing to make the claim that "animals remember other individuals"; it is another to share a story about an individual animal that so powerfully illustrates this very claim. And it is not just classroom discussions that are enriched by anecdotes; academic publications are, too. Had M\&M included 
sheep anecdotes in their target article, the case for sheep mental complexity surely would have been strengthened (see YouTube sample 1, sample 2, sample 3).

Anonymous Sheep. The most compelling work about the mental lives of animals highlights the stories of named animals, rather than discussing animals only in the abstract. For instance, on their website, Farm Sanctuary (2019) writes about a deep familial bond between two sheep, Marjorie and Gabriel (who is Marjorie's son). The two reportedly cry if separated, even for just a few minutes. Farm Sanctuary also writes about Juniper, Zoop, and Pearl - a trio of sheep who, after meeting each other at the sanctuary, became inseparable. Such stories about named sheep draw attention to their sociality, their deep familial bonds, and their individuality.

Given M\&M's emphasis on sheep personality, it might have helped if instead of writing about individual sheep - sheep with names - they merely discussed "sheep" in the abstract. As Wrenn (2018) notes, when we refer to animals only with abstract, mass terms, there is a sense in which individual animals are objectified, obscured, and stripped of their individual identities. Continually referring to "sheep" in the abstract, without any mention of named sheep, supports the impression that they are "one-dimensional, interchangeable units within a group, population, or species" - a view that M\&M (p.13) clearly want to challenge.

Unethical Research. A goal of the target article is to challenge the historical representation of sheep as objects, yet M\&M at times defend their view by drawing on research that reduces sheep to the status of mere tools for research. They refer, for example, to Destrez et al.'s (2013) study on chronic stress in sheep, which involved exposing five-month-old lambs to six weeks of "aversive and unpredictable events related to predation and negative handling." Does not drawing on such terrible "stress" research legitimize it? If citing such research is necessary for making an important point about sheep minds, attention should at least be drawn to its moral atrociousness.

Anthropocentric Research. As M\&M mention, one common method scientists use to demonstrate self-awareness in animals (humans or nonhumans) is the mirror self-recognition test (Reiss \& Marino 2001). In one version, a mark is placed on the body or the forehead of an animal and then the animal is placed in front of a mirror. Researchers assume that if animals understand that the image is of themselves, they will try to take the mark off while looking at the mirror. Animals who do not "pass" the mirror test are said to lack self-awareness because they apparently fail to understand their own reflection.

The mirror test uses only sight, which is the human's superior sense, to test the presence of self-recognition in animals. Many nonhuman animals, however, have poor eyesight. Dogs, for example, rely primarily on scent to navigate the world. Yet, scientists often assume that we should "test" for the presence of self-awareness in nonhuman animals by placing them in front of mirrors. Bekoff (2007) recommends an alternative "self-recognition" test for dogs, which acknowledges the importance of smell in canine life. When conducting what he calls the "yellow snow test," Bekoff moved his dog Jethro's "yellow snow" and the "yellow snow" of other dogs along a bike path. When he brought Jethro down this path, Jethro spent more time sniffing the "yellow snow" of the other dogs. Bekoff interpreted this as indicating that Jethro knew what was his urine and what was others' urine, and thus that he had a sense of "mine-ness." (The discrimination, however, may also have been a result of habituation to one's own odor [Ferdenzi 
et al. 2014]. Some species respond differently to recordings of their own vocalizations, but it is not clear whether this is self-recognition either [Snowden \& Cleveland 1980; Mitchell 1992].)

Mirror tests assume that if human behavior $X$ indicates that humans have capacity $X$, then animals who don't exhibit behavior X lack capacity X. But, as Bekoff notes, sometimes another animal behavior, $Y$, can indicate that they have capacity $X$. It might have been helpful for M\&M to draw attention to this in the context of discussing how mirror tests can inform our understanding of sheep minds.

\section{References}

Bekoff, M. (2007). The emotional lives of animals. New World Library.

Destrez, A., Deiss, V., Leterrier, C., Boivin, X., \& Boissy, A. (2013). Long-term exposure to unpredictable and uncontrollable aversive events alters fearfulness in sheep. Animal, $7(3)$, 476-484.

Farm Sanctuary. (2019). Meet the animals: Sheep and goats.

Ferdenzi, C., Poncelet, J., Rouby, C., \& Bensafi, M. (2014). Repeated exposure to odors induces affective habituation of perception and sniffing. Frontiers in Behavioral Neuroscience, 8, 119.

Kendrick, K. M., da Costa, A. P., Leigh, A. E., Hinton, M. R., \& Peirce, J. W. (2001). Sheep don't forget a face. Nature, 414(6860), 165-166.

Marino, L., \& Merskin, D. (2019). Intelligence, complexity, and individuality in sheep. Animal Sentience 25(1).

Mitchell, R. W. (1992). Developing concepts in infancy: Animals, self-perception, and two theories of mirror self-recognition. Psychological Inquiry, 3(2), 127-130.

Reiss, D., \& Marino, L. (2001). Self-recognition in the bottlenose dolphin: A case of cognitive convergence. Proceedings of the National Academy of Sciences USA, 98, 5937-5942.

Snowdon, C. T., \& Cleveland, J. (1980). Individual recognition of contact calls by pygmy marmosets. Animal Behaviour, 28(3), 717-727.

Wrenn, C. (2018). How to help when it hurts? Think systemic. Animal Studies Journal, 7(1), 149179. 